$\Phi=\Phi$

\title{
Occupational health and safety provision awareness among construction workers on the construction industry of Windhoek , Namibia
}

\author{
Nghitanwa Emma Maano ${ }^{1 *}$, Zungu Lindiwe I ${ }^{2}$ \\ ${ }^{1}$ Doctoral student, Department of Health Studies, University of South Africa, Pretoria \\ ${ }^{2}$ Department of Health Studies, University of South Africa, Pretoria \\ *Corresponding authorE-mail: enghitanwa@unam.na
}

\begin{abstract}
The purpose of this study is to discuss the awareness on the provision of occupational health and safety (OHS) among construction workers in the construction industry of Windhoek, Namibia. A quantitative, descriptive, cross sectional design was applied. Interviewerled questionnaires were used to collect the data among 549 participants. The study results showed that most construction workers express poor awareness on construction industry OHS provision. The interventions such as OHS training enforcement is needed in order to increase construction workers OHS awareness through training. The employees need to establish OHS programs on the construction sites which include the development of the OHS policies which shows organisation commitment towards occupational health and safety of its workers.
\end{abstract}

Keywords: Awareness; Construction Industry; Construction Workers; Occupational Health; Occupational Safety.

\section{Introduction}

Occupational health and safety was defined as a broad concept which entails the physical, mental and psychosocial well-being of the worker in relation to the work and the working environment aimed at providing a safer working environment which leads to an improvement of productivity as well as that of the worker's morale and quality of life (Amponsah-Tawiah \& Dartey-Baah, 2011).The construction workers'awareness of OHS is of great importance as it determines the individual and organisational behaviour (Mwanaumo \& Thwala, 2012). However, a majority of construction workers have a low safety awareness (Zeng et al. 2008), a condition that can have a negative impact on the workers and the organisation (Mwanaumo \& Thwala 2012). A study by Zeng, et al. (2008) which investigated the implementation of an OHS management system in China reveals that a majority of the participants indicated that the existence OHS existence was not satisfactory. A leaders' and project managers' poor awareness of OHS affects organisational safety performance (Zeng et al., 2008). Development and implementation of OHS program is for utmost importance in order to promote healthy and safe workplaces (Arkson \& Hadikusumo, 2008). The OHS program should include OHS policy, emergency plan and provision of first aid services on the construction sites among others (Annan et al., 2015) which should be made available to workers in order to prevent occupational accidents, injuries and diseases. The occupational health and safety policy is one of the elements of an OHS program which states the employer's aims and commitment to the OHS program in order to protect the health and safety of workers (Work Safe Bc, 2013).

Meanwhile, a study on the conditions within Chinese construction companies in Namibia reveals that a majority of the construction workers were not aware of the existence of the OHS policy or OHS-related documents in their respective construction sites (Herbert \& Iipumbu, 2009). It is also imperative that construction workers be aware of the first aiders at their workplaces and the location of the first aid kit in order to get timeous assistance when first aid is required (Irumba, 2014). Furthermore, Hallowell (2008) points out that planning for emergencies reduces the severity of accidents or catastrophic events. In addition, the presence of qualified first aiders is important, hence, first aid services should be provided on site.

\section{Objectives}

The objective of this study is to:

- Describe the socio-demographic characteristics of the participants

- Assess the construction industry workers' awareness of OHS provision.

\section{Methodology}

A quantitative, descriptive and contextual approach was applied in this study. A cross-sectional design was used to assess the awareness of construction workers on OHS provision on different construction sites in Windhoek. This study was conducted on 13 construction sites in Windhoek, Namibia, among the construction workers who were available and willing to participate in the study. The study population in this study consisted of 1097 construction workers in the Windhoek construction industries, who were available during data collection time. However, only 549 construction workers agreed to participate in the study. The list of all construc- 
tion workers was obtained from 13 different construction sites and used as a sampling frame. Census sampling was employed in this study. The inclusion criteria include all construction workers who were available on construction sites in Windhoek, Namibia during data collection time.

Data was collected with interviewer-led questionnaire which was developed by the researchers. Data collection tool was piloted among construction workers with similar characteristics to those participating in the main study to improve the reliability and validity and comments from the participants were incorporated in to the final revised data collection instrument. The pilot study was conducted using sixteen construction workers from two construction sites.

Interviewee-led questionnaires were administered by the researchers to each of the participants on the time agreed upon by the site managers and participants. The purpose of the study was explained and confidentiality was guaranteed. Before data collection could start, each participant was given a consent form to read and sign indicating their understanding of the study purpose and its conditions and agreement to participate in the study. Data was entered in the SPSS software program version 23.0 and a professional statistician, analysed the data.

\section{Results}

\subsection{Socio-demographic characteristic of participants}

The analysis shows that $485(88.3 \%)$ of the participants in this study were males and $64(11.7 \%)$ were females. The participants' age group distribution consists of $235(42.8 \%)$ participants aged between 18 and 29 years followed by $229(41.7 \%)$ occupying the $30-39$ age range, $83(15.1 \%)$ were aged between 40 to 49 years and $2(0.4 \%)$ were aged between $50-59$ years. The mean overall age is 31.48 years. Furthermore, of these workers, 364 (66.2\%) were single, while $37(25 \%)$ were married.

\subsection{Participants' awareness of occupational health and safety (OHS) policy availability and accessibility}

The analysis of data about the participants' awareness of the availability of OHS policy at their respective construction sites shows that $29.9 \%$ reported that they were aware of the availability of OHS policies. In addition, $74.1 \%$ of the participants indicated that they had access to the OHS policy on their construction sites. The analysis also shows that $60.8 \%$ of the participants stated that they did not receive any OHS training. Participants were also asked to indicate whether they were aware of the health and safety representatives at their work places. The analysis of responses regarding the awareness and presence of health and safety representatives shows that $38.68 \%$ of the participants were aware of their representatives' availability at their respective construction sites. The responses regarding an awareness of the availability of the occupational health and safety officers and issues related attendance of safety workshops and measures expected in case of a disaster or accident were analysed. The analysis shows that $39.3 \%$ participants were aware of the available OHS officers at their workplaces. The analysis of responses to the aspect of attendance of safety talks in the construction sites shows that $47.2 \%$ of the participants have attended safety talks at their construction sites. Moreover, $61.4 \%$ of participants were aware of what to do when accidents happen at work

\subsection{Participant's awareness of emergency preparedness procedures and provision of first aid services at con- struction sites}

Participants were asked to state whether they were aware of any emergency plan at their respective construction sites. The analysis shows that $85.4 \%$ of the participants indicated that they were not aware on the existence of an emergency plan at their workplaces, regarding the attendance of emergency training at work, the analysis illustrates that $84.7 \%$ of the participants had never attended emergencies training at work. In addition, a lesser number of $49.7 \%$ participants were aware of the availability of first aiders at their construction sites. Finally, the analysis shows that $53.9 \%$ of the participants were aware of the location of the first aid kits.

\section{Discussion}

\subsection{Socio-demographic characteristics of participants}

The findings from this current study shows that male participants where significantly many comparing to female. This finding is consistent with construction industries several demographic data such as (Lee , 2010 ) in Hong Kong and Watts (2009) study on women managers in the UK construction industry and Roche et al., (2015) study on workers alcohol use in male-dominated industries in Australia. These authors indicated that construction industry is male dominated. In contrast, Baruah's (2010) study on women in India construction industry revealed that construction industry is female dominated where women constitute $51 \%$ of construction workers. Construction industry is male dominated as males tend to work in the construction industries due to the nature of work which requires a person to be physically fit.

More than two- fifths of the participants were aged between 18 to 39 years. This study findings are almost similar with the study conducted in Tanzania construction industry were $56.3 \%$ participants were aged 25- 35 years (Phoya 2012).Similar,Miller (2012) conducted the study to assess the educational safety training solutions for Latino construction workers, where the findings revealed that overwhelming majority, $78 \%$ of participants were younger than 40 years. However, the current study finding is in contrary with the study conducted in construction industries by (Eppenberger \&Haupt (2009) in South Africa were by the majority of participants were aged above 40 years. The finding of the current study indicates that construction industry is dominated by young population who are vulnerable and less experienced (SuárezCebador et al., 2015).

The current study findings indicated that just below two-thirds of participants were single. The findings are supporting the study conducted in Portuguese construction industry which stated that construction industry is known to mostly employ single young men ( Arezes \& Bizarro, 2011).This current study finding is not supported by studies conducted in the construction industries by other authors, such as Rahmani et al.,(2013) in the study about accidents among electricity distribution company workers in Iran and Liao and Chiang's (2016) study about reducing occupational injuries in Taiwan construction industry which shows that , 63\% and $63.7 \%$ construction workers were married. According to the 2011 census, just below three-fifths of the Namibian population were single (Namibia Statistic Agency, 2013) which possibly influence the construction industry working population to be single.

\subsection{Participant's awareness of occupational health and safety provision}

The study revealed that just below three-tenth of the participants indicated that they were not aware of OHS policies existence in their workplaces during the current study. This finding is similar to the study by Herbert and Iipumbu (2009) who conducted a study in a Namibian construction industry which found out that the majority of construction workers were not aware of the existence of OHS policy or OHS related documents. In contrary, Niskanen et al., (2012) conducted a study to evaluate European Union legislation concerning risk assessment and preventive measures in OHS which found out that the overwhelming majority $(88 \%)$ of participants indicated that they were aware of OHS policy availability at their workplaces. The finding of the current study is implying poor awareness of OHS as possibly there were 
no policy available in some sites or the policy was developed without workers involvement. Availability of OHS policy in the organization contributes to occupational accidents and injuries reduction (Aneziris et al., 2012).

The current study findings indicated that the majority of the participants indicated that OHS policy were not accessible. The current study findings are against the provision made in regulation 3 of the Regulations relating to health and safety of employees at work (No. 156 of 1997) which states the responsibility of the employer to ensure that the OHS policy is accessible (Republic of Namibia, 1997). The result of this study implies that the employers are not adhering to the regulatory requirement which could be explained by non-accessibility of OHS policy. Additionally, the current study findings shows that just below two-fifths of the participants indicated that they had OHS training. The findings are in line with several authors findings from construction industries studies such as (Cheng et al., (2012) only (25\% ) in Taiwan, Irumba(2014) (45\%) in Uganda and Phoya (2012 ) (25\%) in Tanzania, as these authors indicated that only few participants were found to be trained on OHS . However, findings are in contrary to the study by Miller (2012) on assessment of educational safety training for Latino construction workers which found out that all respondents indicated that they had received OHS training. This current study finding is showing that many construction workers lack OHS awareness possibly to the fact that they did not receive OHS training. Lack of OHS training is affecting the awareness of workers especially on accident prevention which will leads to high accidents and injuries at work (Taylor, 2015). It was found out that more than three-fifths of the participants were not aware of the availability of health and safety representatives at their respective sites. This current study finding is different from the study conducted in the construction industry of Spain to assess the impact on OHS as it revealed that the majority ( $85.3 \%$ ) of construction workers were aware that they had OHS representatives (OlléEspluga et al., 2015). Occupational injuries and accidents reduced in the workplaces with OHS representatives (Ollé-Espluga et al., 2015).

Furthermore, it emerged from the findings of the current study that above three-fifths of the participants were not aware of OHS officers in their sites. This is different from a study conducted by Ngamthampunpol (2008) in Thai construction industry whereby the majorities $(87.68 \%)$ of participants were aware that OHS officers were available in their respective construction sites. However, this current study findings is not supporting Irumba's (2014) study in Uganda construction industry were by only few OHS officers were employed in $30 \%$ construction sites. Moreover, the unavailability of safety officers in the construction sites is promoting poor working condition and negatively affecting safety because the availability of knowledgeable health and safety officers improves site safety (Bleck and Wettberg, 2012).Therefore, OHS officer appointment at the construction sites should be enforced. The current study findings also indicated that only above fourninths of the participants indicated that they have attended safety talks at the study sites. The findings are different with the study by Olson et al., (2016) on evaluation of toolbox talks in USA construction industry in fatality prevention which found out that $25 \%$ of employers never conducted safety talk. Safety talk is the best organisational safety practice which increase hazard awareness, increase knowledge and skills and motivate workers. The majority of the participants had never attended emergencies training at work. According to the (Work SafeBc , 2008) report ,workers should be trained on emergencies that could happen at work. Furthermore, according to the ILO-OSH (2001) the employer should ensure that workers are involved in their own safety which include the awareness regarding emergency so that they will be able to act properly during emergency. The findings for this current study indicated that just below two-fifths of the participants indicated that they knew that hazard control is being performed at workplaces. The current study finding is not supporting the study by Ngamthampunpol (2008) study in Thai construction industry where the majority of the respondents $(92.03 \%)$ indicated that the proper engineering technique was used in the construction sites to control hazards.

\section{Ethical issues}

As this was a research involving human subjects, an ethical clearance was obtained from the University of South Africa (UNISA) research ethical committee before data collection process. Furthermore, permission was sought and obtained from the site managers of the construction sites which participated in the study before data collection. The aim of the study was explained to the participants and they were informed about confidentiality and anonymity as well as their right to withdraw from the study any time if they wish. Participants were also asked to sign the informed consent which shows that they gave permission to participate in the study. The signed consent forms were placed in a box separate from the questionnaire to maintain anonymity, and this was followed by the researchers interviewing participants. No rewards were given to the participants.

\section{Conclusions}

The study investigated the awareness of OHS provision among construction workers. The study findings revealed that construction workers have poor awareness of OHS provisions. In addition, participants indicated the lack of OHS training on the construction sites which contributed to poor OHS awareness. The lack of OHS policy in many construction sites revealed the absence of occupational health and safety programs in different construction sites. Interventions are needed in order to improve awareness of construction workers on OHS provisions. OHS training among construction workers and development of OHS programs in the construction sites would improve construction workers awareness.

\section{Acknowledgement}

The study was conducted with the permission from the University of South Africa and construction site managers for different construction sites. The researchers would like to thank construction workers who participated in the study.

\section{References}

[1] Aksorn, T \& Hadikusumo, BMW. 2008. Critical success factors influencing safety program performance in Thai construction projects. Safety Science. 46: 709-727. https://doi.org/10.1016/j.ssci.2007.06.006.

[2] Amponsah-Tawiah, K \& Bartey-Baah, K. 2011. Occupational health and safety: Key issues and concerns in Ghana. International Journal of Business and Social Sciences 14(2):119-126.

[3] Aneziris, ON, Papazoglou, IA, Konstandinidal, M, Baksteen, H, Mud, M, Damen, M, Bellamy, LJ \& Oh, J. 2013. Quantification of occupational risk owing to contact with moving parts of machines. Safety Science 51:382-396. https://doi.org/10.1016/j.ssci.2012.08.009.

[4] Arezes, PM \& Bizarro, M. 2011. Alcohol consumption and risk perception in the Portuguese construction industry. The Open Occupational health and Safety Journal 3(suppl 1-M2):10-17.

[5] Baruah, B. 2010. Gender and globalization. Opportunities and constraints faced by women in the construction industry in India. Labour Studies Journal 35(2):198-221. https://doi.org/10.1177/0160449X08326187.

[6] Bleck, D \& Wettberg, W.2012. Waste collection in developing countries. Tackling occupational safety and health hazards at their sources. Waste Management 32:2009-2017. https://doi.org/10.1016/j.wasman.2012.03.025.

[7] Eppenberger, M \& Haupt, T. 2009. Construction worker injuries and costs - a comparative study of older and younger workers. Occupational Health Southern Africa (September/ October):6-13.

[8] Hallowell, MR. 2008. A formal model for construction safety and health risk management. Doctoral thesis. Oregon State University: Oregon. 
[9] Herbert, J \& Iipumbu, S.2009. Chinese Investments in Namibia, a labour perspective. Windhoek: Labour Resource and Research Institute.

[10] International Labour Organization. 2001. Guidelines on occupational safety and health management systems. Geneva. Switzerland: ILO Publications.

[11] Irumba, R. 2014. Spatial analysis of construction accidents in Kampala, Uganda. Safety Science 64:109-120. https://doi.org/10.1016/j.ssci.2013.11.024.

[12] Lee, WH. 2010. Relationship between safety climate and occupation accident in Hong Kong construction industry. Msc dissertation. Hong Kong Baptist University. Hong Kong.

[13] Mwanaumo, E \& Thwala, WD. 2012. Construction practitioners' awareness of occupational diseases in the Botswana construction industry: An exploratory study. Occupational Health Southern Africa $18(4): 12-17$.

[14] Miller, MR. 2012. Assessing an educational safety training solution for Latino construction workers. MA Dissertation. Colorado: Colorado State University.

[15] Namibia Statistic Agency. 2013. Namibia Population and Housing Census. Government of Namibia. Namibia.

[16] Ngamthampunpol, D. 2008. An assessment of Safety Managemen in the Thai construction industry. Doctoral Dissertation. George Washington University, United States.

[17] Niskanen, T, Naumanen, P \& Hirvonen, ML, 2012. An evaluation of EU legislation concerning risk assessment and preventive measures in occupational safety and health. Applied Ergonomics 43(5):829-842. https://doi.org/10.1016/j.apergo.2011.12.003.

[18] Olle-Espluga, L, Vergara-duarte, M, Belvis, F, Menéndez-Fuster, M, Jódar, P \& Benach, J. 2015. What is the impact on occupational health and safety when workers know they have safety representatives? Safety Science 74:55-58 https://doi.org/10.1016/j.ssci.2014.11.022.

[19] Phoya, S., 2012. The practice of risk assessment, communication and control health and safety risk management in building construction sites. Degree thesis. Chalmers University of Technology: Gothenburg, Sweden.

[20] Rahmani, A, Khadem, M, Madreseh, E, Aghaei, H, Raei, M \& Karchani, M, 2013. Descriptive study of occupational accidents and their causes among electricity distribution company workers at an eight-year period in Iran. Safety and Health at Work 4(3):160-165. https://doi.org/10.1016/j.shaw.2013.07.005.

[21] Roche, AM, Lee, NK, Battams, S, Fischer, JA, Cameron, J \& McEntee, A. 2015. Alcohol use among workers in male-dominated industries: A systematic review of risk factors. Safety Science 78:124-141. https://doi.org/10.1016/j.ssci.2015.04.007.

[22] Suárez-Cebador, M, Rubio-Romero, JC \& Lòpez - Arquillos, A. 2014. Severity of electrical accidents in the construction industry in Spain. Journal of Safety Research. 48: 63-70. https://doi.org/10.1016/j.jsr.2013.12.002.

[23] Taylor, EL. 2015. Safety benefits of mandatory OSHA 10h training. Safety Science. https://doi.org/10.1016/j.ssci.2015.03.003.

[24] Watts, JH. 2009. Leaders of men: women 'managing' in construction. Work, Employment and Society 23(3):512-530. https://doi.org/10.1177/0950017009337074.

[25] WorkSafe Bc. 2008. How to implement a formal occupational health and safety program.

[26] From: http://www.worksafebc. Com/publications/health and safety/ by topic/assets/pdf/ how to implement_ohs. Pdf (accessed 20 April 2015).

[27] Zeng, SX, Tam, VWY \& Tam, C. 2008. Towards occupational health and safety systems in the construction industry of China. Safety Science 46(8):1155-1168. https://doi.org/10.1016/j.ssci.2007.08.005. 